\title{
Capítulo 1. \\ El olvido de los demás: El surgimiento del nuevo narciso
}

Zn la actualidad, ya no predomina el ideal de una ética del deUber, precisa Lipovetsky $(1983)^{1}$, sino que se ha entronizado al individuo a tal punto que lo que se promueve es una moral indiferente a lo social, anclada en el individualismo llevado al extremo. Dicha moral ya no se aprende en la escuela sino que la pregonan los medios de comunicación, los cuales han logrado desacralizar la tarea del maestro y han banalizado la escuela, convirtiéndola en una máquina neutralizada por la indiferencia escolar, al considerarla aburridora.

Lipovetsky se constituye en un crítico acérrimo de los medios de comunicación, al considerarlos causantes de una amnesia permanente y promotores del olvido y, en parte, de la indiferencia. La que educa ya no es la escuela, sino los medios de comunicación con sus shows mediáticos, con sus espectáculos de luces, sonidos y mujeres y hombres voluptuosos, promoviendo estereotipos

1 Nació en Paris en 1944, estudió en la Sorbona en Grennoble, donde en la actualidad es profesor. en 1983 publicó su obra principal, La era del vacío, donde profundizó sobre lo efímero y lo frívolo. En su segunda obra, El imperio de los efimero (1987) aborda temas como la moda y su destino en las sociedades modernas. 
por seguir. En este contexto, la educación se ve obligada a ondear la bandera de la innovación para enfrentar los "golpes" nocivos y cegadores de los massmedia.

Desde la antigüedad se ha considerado al ser humano un ser complejo, incomprendido, misterioso y paradójico; realidad que se puede constatar en lo afectivo, lo político, lo religioso, lo económico y en lo social. Desde el punto de vista social, el ser humano efectivamente necesita de los otros desde el nacimiento, pasando por su etapa prepuberal hasta los días de su fenecimiento. Sin embargo, actualmente, se ha vendido la idea de que podemos salir avante en nuestros proyectos, esforzándonos individualmente, y alejándonos de los demás. Así como también se nos ha ofrecido la idea de que podemos desenvolvernos en guetos, donde la identidad se pueda construir al identificarse con alguna tribu, en su vestimenta, su música, su "ideología”, sus gustos. Ambos son extremos, el individualismo y el tribalismo. En este capítulo se expondrán estos dos fenómenos.

\section{Eclosión del nuevo narciso}

Actualmente, el hombre está prisionero de los grandes grupos económicos transnacionales que, con sus medios de información y su gran estrategia publicitaria, nos venden todo lo que crean y en muchos casos, cosas obsoletas que terminan atiborrando nuestros desvanes y que al final inundan nuestro planeta de basura. También, nos venden el ideal de un individuo exitoso, que puede conquistar lo que se proponga, sin importar muchas veces el daño que se le pueda generar al ecosistema y a los demás. Nos venden un paradigma de individuos exitosos, pero que están inmersos en una sociedad fracasada, inequitativa, resquebrajada. ¿Cómo es posible, que solo el $10 \%$ más rico de América Latina y el Caribe posee el $71 \%$ de la riqueza, y que solamente tributa el 5,4\% de 
su renta? (CEPAL, 2016). Esto es deplorable, injusto y alarmante, situación que impele a empuñar las banderas de la solidaridad para que esto no suceda, y se reparta equitativamente la riqueza.

¿De qué vale tener riquezas, si muchas veces no hay con quien compartirlas? Tal vez gastarla en objetos suntuosos, en sexo, drogas, viajes, yates, carros lujosos, pero ¿acaso esto colma el corazón del hombre? Tristemente un enorme vacío llena los espacios de la soledad del individuo. El dinero se ha convertido en un fetiche, en un centro de adoración; se ha perdido el horizonte, el dinero ya no es un medio, sino el fin, el rey, el motivo de todo: "Tener un buen auto, viajar al exterior, rodearse de objetos útiles, no es malo. Lo malo consiste en olvidar que son medios para otro fin: la vida, la mía, la tuya, la nuestra" (Barylko, 2012, p. 10).

A esta vivencia de soledad se une la idea de la incomunicabilidad del ser humano, pues paradójicamente, en nuestro tiempo, el hombre ha avanzado en comunicaciones con sus satélites, sus redes y sus teléfonos inteligentes; sin embargo, cada vez se comunica menos. Nuestras relaciones están siendo mediatizadas por máquinas, puesto que pasamos más tiempo con nuestro celular, en WhatsApp, en Facebook que con nuestras familias, nuestros hijos y nuestros amigos. La realidad virtual se está apoderando de la verdadera realidad. Estamos asistiendo a una paradoja, pues a pesar de tener más de un millar de amigos en las redes sociales, nos asiste una sensación de vacío, de soledad: "El hombre suelto, el del teléfono móvil, se comunica constantemente con otros, y cuando cierra el celular, siente cuán solo es. Es, no está... El hombre del siglo XXI es un monumento al ser solo" (Barylko, 2012, p. 21).

Sumada a la soledad del individuo contamos con otra problemática no menos preocupante que la anterior, y es la de una sociedad carente de tiempo: "El hombre no dispone de tiempo. Es el lema mayor en su escudo de armas: No tengo tiempo...No tenemos tiempo porque le tememos al tiempo. Me deja solo, me obliga a pensar. Y brotan las preguntas: ¿Qué hago ahora? ¿Para 
qué estoy? ¿A dónde voy? ...La diversión es para pasar el tiempo" (Barylko, 2012, p. 59). Es una realidad que merece atención, puesto que para cuidar a los otros y cuidarnos, el tiempo se erige en un factor clave e indispensable; si se carece de tiempo para invertir en los cuidados de la salud, se tendrá que gastar tiempo en los cuidados que exige estar enfermo; tópico que será abordado más adelante por la relevancia que demanda en el presente.

Siguiendo con la caracterización del ser humano actual, el hombre se encuentra atrapado por el consumo, por la compra desaforada de cualquier artilugio que lo entretiene. Se destaca lo festivo, el juego, los realities, los showes. La vida se convierte en un espectáculo permanente donde importa el goce, la satisfacción de los deseos, se ha creado un imperio alrededor del Homo Consumens cuya médula espinal consiste en un ethos hedonista, donde la relación con el otro está mediada por lo que se consume, por aquello que se compra y lo que se posee. Desafortunadamente, detrás de las relaciones interpersonales se oculta un provecho particular; inclusive las relaciones afectivas y familiares han caído en la desfachatez del interés particular. El interrogante de fondo sería ¿qué puedo ganar con esta amistad, sabiendo que ese ganar se limita casi exclusivamente a lo económico?

Por otra parte, el campo político también se ha visto afectado por la dinámica economicista. Pareciera que todo se encuentra en venta, se venden conciencias por unos cuantos pesos. Cunde una especie de escepticismo político, pues ya los individuos no se comprometen con la vida pública, la democracia es un cuento de hadas, los políticos corruptos se han aliado con la publicidad para anestesiar las conciencias, y mediante cortinas de humo, como el fútbol, los realities y las telenovelas, distraen a las multitudes para lucrarse con el erario público.

Desde otro ángulo, en el plano ético, poco importa el cómo se actúa. Importa más la fachada, el exterior, el cómo verse frente a los demás. Lo ético ha cedido el puesto a lo estético. Aunque 
mantener esa fachada resulte demasiado costoso, muchos se las arreglan para conseguir el dinero, la mayoría de las veces sin escrúpulos; pues si para tal fin es necesario vender hasta la conciencia y su propio cuerpo, o entrar en redes delincuenciales, se arriesgan, sin medir las consecuencias.

El mundo facilista también ha entrado en el plano educativo. Se percibe una falta de compromiso en muchos estudiantes y docentes, se carece de escrúpulos y se cae en la desidia fácilmente. La educación en el aula se ve notablemente afectada por este fenómeno. Lo que se enseña en el colegio fastidia, genera indiferencia, lo que exige esfuerzo se evade, la atención está dispersa o en los móviles telefónicos que logran entretener o en aquellos maestros que hacen maromas para captar la atención de unos individuos demasiado apáticos. Lo que nos dice el filósofo francés es que falta el show, al respecto escribe:

Hacen falta la fiesta, el rock, los conciertos y las exposiciones bonachonas plagadas de eslóganes de tono humorístico-publicitario. Ahora los actores sociales abrazan el universo de la imagen, del espectáculo, de los media, del estrellato, de la moda, de la publicidad... (Lipovetsky, 1983, p. 320)

El nuevo narciso, que centra la atención en sí mismo y se olvida de los demás, poco se compromete, evade responsabilidades, se desentiende de los problemas sociales como la indigencia, la miseria, la corrupción, la inequidad. En muchas ocasiones el compromiso se limita a participar en algunas marchas esporádicas, o en llenar de memes las redes sociales, manifestando así su “indignación". Es una protesta ligera, sin sacrificio. En el ideal antropológico contemporáneo escasean los espíritus filantrópicos y generosos.

Asistimos a una sociedad donde el hombre vale por lo que ostenta y no por lo que es. En el modelo económico imperante muchos son excluidos, y son muy pocos los servicios públicos de 
buena calidad que ofrece el Estado a causa de la burocracia y la deshonestidad por parte de algunos funcionarios, quienes ven en lo público la oportunidad para lucrarse, mientras que en el sector privado, los servicios suelen ser de buena calidad pero a costos exacerbados.

En la sociedad actual, el hombre está anegado por el consumo y los monopolios económicos. Mediante sus estratagemas de mercado ofrecen la posibilidad de "elegir" lo que se debe consumir, cómo vestirse, qué estudiar, qué leer, qué programas ver, qué pócima tomar, o qué crema aplicarse para adelgazar o para no envejecer. Asistimos a un momento donde no hay cabida para los pobres, los feos, los gordos, los defectuosos y los viejos. Se nos vende un modelo inmaculado de estética, unas medidas perfectas y unos cuerpos esculturales cual modelo recién salido de gimnasio. $\mathrm{Al}$ respecto, Lipovetsky denuncia:

La estructura narcisista del Ego domina; por un lado, se trata de tener dinero para gozar en privado de los bienes y servicios de la vida moderna y por otro, de hacer algo por sí y para sí mismo, conocer la excitación, la aventura o el riesgo. (Lipovetsky, 1983, p. 287)

Se trata de una sociedad atosigada por el consumo, donde el nuevo oficio es el de comprar sin importar aquello que se compre, puesto que el imperativo es que se consuma. En este nuevo oficio, el hombre descarga todo el cansancio y el aburrimiento que le ocasiona su trabajo y, de la misma manera, calma la ansiedad que le produce su existir. En este contexto, quienes no tienen los medios para entrar en esta dinámica del consumo quedan totalmente excluidos de la sociedad. Ellos deben hacer hasta lo imposible para conseguir el dinero que les permita el lujo de tener, no importa si les toca vender su dignidad, su reputación, y mucho menos, si les toca renunciar a sus principios; casi todo se negocia por dinero. La gente se ha transformado en un producto que se vende y 
se compra con el propósito de obtener dinero. Para el hombre de hoy no hay elección, toca comprar sin importar si la casa es de tablas o de barro. Solo importa contar con los aparatos tecnológicos de última generación, o el celular más novedoso. $\mathrm{Al}$ respecto el sociólogo Bauman, escribe:

Tener recursos significa tener libertad de elegir, pero también - y eso es lo más importante - significa tener libertad de soportar las consecuencias de las malas elecciones y, por lo tanto, libertad del atributo menos deseable de la vida de elección. (Bauman, 2003, p. 22)

En últimas, pareciera que el hombre contemporáneo fuera un ser para el consumo, para las compras, para la diversión, un ser que segrega al prójimo y que sucumbe ante el dinero, como un niño ante una golosina o un juguete. Como denunciara el pensador francés Redeker:

[...] calificar al hombre contemporáneo como un hombre nuevo, por más que pudiéramos ver en él una entidad históricamente inédita, no es pertinente, en la medida en que este ser es el producto del consumo, de la publicidad y de las industrias del entretenimiento. (Redeker, 2014, p. 64)

Otro tópico que no podemos desconocer en la actualidad guarda relación con la industria del entretenimiento, donde emergen dispositivos electrónicos que han calado fenomenalmente en los individuos; dispositivos, por cierto, costosos y en ocasiones inaccesibles para un gran número de personas; sin embargo, muchos comprometen hasta años de trabajo entero con tal de ostentar el último grito de la moda. Es común ver a muchos jóvenes pegados a las pantallas, "conectados", atrapados por la red, atrapando pokemones o, en su defecto, acoplados a comunidades virtuales. Para Redeker este hombre está inmerso en el vacío: 
Este nuevo hombre difunde permanentemente a su alrededor como un aura insignificante, una impresión patógena de vacuidad; con frecuencia es un hincha en los estadios de fútbol u otros. De hecho, el ruido del deporte lo mantiene en el pensamiento. Mejor aún, el deporte se difunde bajo la forma del ruido de fondo de su inteligencia. Bajo su forma femenina, el hombre nuevo, llena las salas de los gimnasios donde brinca con la música. (2014, p. 67)

En los escenarios escolares prolifera este tipo de persona, que está subordinado por el consumo y se encuentra arrodillado a los pies de la industria del entretenimiento. En la escuela ya no se quiere estudiar, los ambientes lúdico-recreativos se han entronizado, el aprendizaje ha sido relegado, lo que importa es "pasarla bien", que los niños disfruten, evitar la exigencia al máximo, y promover valores como la cooperación y la solidaridad, aunque sea de manera superflua. Tras esta falacia de la solidaridad que se intenta cultivar en la escuela, se encuentra un discurso de competencia, donde uno gana y muchos pierden, donde se vende la idea del "éxito"; individuos "exitosos" pero en sociedades colapsadas.

Funestamente, el escenario educativo ha sido uno de los espacios más afectados por esta concepción antropológica actual, puesto que le ha tocado lidiar con seres humanos indiferentes, irresponsables, hedonistas, tacaños, indolentes y egoístas, que ven a los profesores como medios y no como fines. Los individuos terminan siendo amantes de la diversión y de la anomia, las normas están mandadas a recoger y solo queda la mediocridad y algunas veces la transgresión. Frases como "hecha la ley, hecha la trampa" son tenidas en cuenta como políticas de vida y orientadoras del actuar.

En la misma línea, impera la preocupación por la imagen, por la búsqueda de valores ligeros que no comprometen; por figurar, mostrar la imagen y ganar "amigos en las redes sociales", como lo asevera Redeker, “el hombre contemporáneo no ve más allá de su 
pantalla. A imagen de los cavernarios esclavos platónicos, su rostro está pegado a la pared-pantalla" (Redeker, 2014, p. 71).

Concluyendo, se podría afirmar que el ser humano actual se aproxima mucho a la perversidad, se constituye en una versión distinta de lo que debería ser, ha convertido el dinero en fetiche, olvidándose de los otros y posibilitando la eclosión de un nuevo narciso que se interesa por figurar y ser el centro del espectáculo.

\section{El tribalismo como tendencia}

Frente a la visión de un narcicismo contemporáneo, Maffesoli considera que el humano se caracteriza por conformar grupos cuya identidad queda parcial o totalmente diluida en lo colectivo. Michel Maffesoli ${ }^{2}$ piensa que en la actualidad no es que haya una individualización extrema, sino que existe una tendencia a la conformación de tribus, de subculturas, de grupos de individuos que se buscan por afinidades o por aspectos comunes. Según lo manifiesta:

Se trata de microgrupos emergiendo en todos los campos (sexuales, religiosos, deportivos, musicales, sectarios) [...] Así la imagen del tribalismo simboliza el reagrupamiento de los miembros de una comunidad específica con el fin de luchar contra la adversidad que los rodea. (Maffesoli, 2009, p. 10)

La cohesión de estos grupos es fraguada por afinidades musicales, deportivas e ideológicas, entre otras. En Colombia, por ejemplo, hay grupos simpatizantes del liberalismo, otros de la izquierda

2 Michel Maffesoli (Hérault, 14 de noviembre de 1944), sociólogo francés, se le atribuye el haber popularizado el término tribu urbana. Es pionero de la sociología de la vida cotidiana y ha escrito más de una veintena de libros, entre ellos cabe mencionar: El tiempo de las tribus (1990) y La transformación de lo político. La tribalización del mundo postmoderno (2005). 
democrática entre los que podemos citar al Polo Democrático ${ }^{3}$, $\mathrm{MOIR}^{4}, \mathrm{JUCO}^{5}$, y otros progresistas. Muchos de estos jóvenes tienden a hacer parte de estos grupos porque siguen creyendo en una transformación política que se puede alcanzar trabajando desde las bases. Otros consideran que es posible luchar contra la incertidumbre y el vacío del narciso contemporáneo, y abrigan la esperanza de darle sentido a sus vidas refugiándose en este tipo de actividades, según lo afirma Maffesoli:

La búsqueda de actividades asociadas a los deportes de alto riesgo, el ecoturismo, los grandes festivales culinarios, sexuales, artísticos, musicales, los viajes exóticos, así como los programas televisivos de concurso y los conocidos reality showes son una prueba de este cotidiano que trata de combatir conjuntamente a una cotidianidad aseptizada heredada de un racionalismo demasiado mecanicista. (Maffesoli, 2009, p. 13)

Pero no solo se busca salir del vacío en el que muchos se encuentran sumidos, sino que, a través de fiestas, juegos y diversiones de toda índole pretenden liberarse de aquellos códigos o normas que se les han impuesto, de mofarse de sus dioses, de sus leyes y sobresalir mostrándose como contestatarios y, muchas veces, hasta llegar a la situación de subversivos sociales. Ahora bien, estos grupos terminan siendo en muchos casos "clubes" exclusivos, donde no solo hay cabida a la aceptación, sino que muchas veces se presenta el fenómeno de la exclusión, el desprecio y hasta la estigmatización, pues, "quien no tenga el olor de la jauría es, inexorablemente, repudiado" (Maffesoli, 2009, p. 32).

3 Partido político colombiano con tendencia ideológica de izquierda.

4 Movimiento Obrero Independiente y Revolucionario.

5 Juventud Comunista de Colombia. 
Para Maffesoli es claro que este proceso tribal ha permeado todas las esferas de la vida de los individuos, desde la universidad, pasando por la política, hasta llegar al plano de las creencias religiosas. El afecto, las emociones y los sentimientos terminan haciendo parte de este proceso empático y que, para Maffesoli, no se trata solo de mirar si está bien o mal, sino de reconocer que es a partir de este fenómeno como se erige la vida en sociedad, y no del individuo aislado como lo defiende Lipovetsky. $\mathrm{Al}$ respecto asevera Maffesoli:

El proceso tribal ha llegado a contaminar el conjunto de las instituciones sociales. Y es en función de los gustos sexuales, de solidaridades de pensamiento, de relaciones amistosas, de preferencias filosóficas o religiosas que van a instalarse las redes de influencia, los compadrazgos y otras formas de ayuda mutua que constituyen el tejido social. Redes de redes en las que el afecto, el sentimiento, la emoción bajo sus diversas modulaciones desempeñan un papel esencial. No viene al caso decir si esto está bien o mal. Más vale reconocer que, contrariamente a un social racionalmente pensado y organizado, la socialidad no es más que una concentración de pequeñas tribus que tratan, como pueden de conjuntarse, de entenderse, de arreglárselas [...] Lo que es seguro es que ya no es a partir del individuo, poderoso y solitario, fundamento del contrato social, de la ciudadanía deseada o de la democracia representativa defendida como tal, que se constituye la vida en sociedad. (Maffesoli, 2009, p. 34)

Ahora bien, una fortaleza del tribalismo puede radicar en el hecho de que nos podemos cuidar entre nosotros, pues al tener simpatía por algunos los puedo tratar como hermanos, dado que ya hay una especie de cercanía por los intereses similares, fenómeno por el que tiende a aflorar más rápido la solidaridad, la generosidad; y esto, al menos dentro de los grupos de orientación religiosa, suele darse con mayor regularidad. Ahora bien, la solidaridad 
y aceptación del otro no siempre se da en estos grupos, sino que en muchas ocasiones se presenta el fenómeno de la humillación y la creación de una serie de jerarquías que, en vez de unir, disuelven y generan rivalidad y competencia; y lo que es peor, terminan aprovechándose de los otros para escalar y llegar a posiciones notables, de prestigio y de reconocimiento.

Otro fenómeno que se puede presentar en el tribalismo es que el individuo pierde su autonomía y hasta su identidad, muchas veces por favorecer intereses de terceros: "la pérdida de sí mismo, del gasto y otros mecanismos de pérdida que ponen en relieve la apertura, el dinamismo, la alteridad, la sed del infinito" (Maffesoli, 2009, p. 36); esto termina llevando a las personas a situaciones de depresión, a la soledad y, muchas veces, a la pérdida del sentido de su existencia, en una paradoja donde la persona, estando acompañada, se siente sola, puesto que, si bien el grupo la hace sentir plena en algunos aspectos, en otros la terminan dejando en una terrible decepción, porque frente a problemáticas afectivas, familiares y existenciales, el grupo no puede hacer absolutamente nada.

Cabe resaltar que así como el tribalismo puede generar redes de cooperación, también puede suscitar escenarios donde aflore la naturaleza conflictiva de los seres humanos y, que en vez de ayudar, muchas veces se terminan consolidando diferencias insoslayables que al final pueden desencadenar odios, frustraciones y resentimientos:

La fusión de la comunidad puede ser perfectamente desindividualizante; crea una unión que no implica la plena presencia ante el prójimo, sino que establece más bien una relación vacía que yo llamaría relación táctil: en la masa nos cruzamos, nos rozamos, nos tocamos, se establecen interacciones, se operan cristalizaciones y se forman grupos. (Maffesoli, 2009, p. 146)

La vivencia de una ética del cuidado exige no solamente denunciar situaciones deshumanizantes, no ser simplemente espectadores, 
sino actores del cambio, de la reforma, de las transformaciones que se requieran. Exige propiciar escenarios de humanización y de responsabilidad conjunta para con los miembros de nuestra comunidad, en particular, y en bien de nuestro planeta: "Echarse una mano, encontrar nuevas formas de solidaridad, de generosidad, instalar dispositivos caritativos, todas estas son oportunidades para vibrar juntos, para expresar ruidosamente el placer de estar juntos" (Maffesoli, 2009, p. 38).

Ante este fenómeno urge tomar conciencia de que un individuo que se subsume en un determinado grupo perdiendo su identidad necesita encauzar sus energías y sus prelaciones, a sabiendas de que tanto el individualismo como el tribalismo tienen prácticas de segregación y de exclusión. Es apremiante apostar por modelos de humanidad, donde se enfatice el cultivo de valores como la convivencia, la tolerancia, el compartir, la empatía, la solidaridad, el respeto, el diálogo y la corresponsabilidad. Se trata de crear un modelo que emerja como una contracultura que, en vez de promover el éxito, la competencia individual y estereotipos nefastos, se preocupe por fomentar el diálogo, la reflexión, el debate y el aprender a vivir juntos. Se piensa que un modelo que apunte a esta línea guarda relación con la ética del cuidado, con una antropología donde el otro cuenta y donde se trabaje por el bienestar general, donde el tiempo resulte importante y la reflexión sea una labor constante. 
